\title{
Current Management of Residual Excessive Daytime Sleepiness Due to Obstructive Sleep Apnea: Insights for Optimizing Patient Outcomes
}

\author{
Reena Mehra $\cdot$ Raphael Heinzer $\cdot$ Pablo Castillo
}

Received: August 12, 2021 / Accepted: October 1, 2021 / Published online: October 18, 2021

(C) The Author(s) 2021

\section{ABSTRACT}

Although excessive daytime sleepiness (EDS) attributable to obstructive sleep apnea (OSA) can be resolved by consistent usage of and effective treatment (often with the use of continuous positive airway pressure therapy), $12-58 \%$ of patients report residual EDS (REDS). While REDS is difficult to treat, a proportion of cases are possibly due to reversible issues, and wake-promoting medications can prove useful for the remaining cases. Given the challenges associated with effective management of REDS

R. Mehra $(\bowtie)$

Sleep Disorders Center, Neurologic Institute, Cleveland Clinic, 9500 Euclid Ave, S-73, Cleveland, $\mathrm{OH} 44195$, USA

e-mail: MEHRAR@ccf.org

R. Heinzer

Center for Investigation and Research in Sleep,

University Hospital of Lausanne, Lausanne,

Switzerland

R. Heinzer

Pulmonary Department, University Hospital of

Lausanne, Lausanne, Switzerland

P. Castillo

Mayo Clinic, Jacksonville, FL, USA and its relationship to multiple comorbidities, multidisciplinary management of patients with REDS is often recommended. Here we aim to bridge the knowledge gap on the burden, risk factors, prevalence, and potential pathophysiologic mechanisms of REDS in patients with OSA after first-line treatment. The roles of primary care physicians and sleep specialists, as well as the importance of the use of objective assessment tools for the evaluation of REDS and the effective management of comorbidities, are discussed. An update of approved treatments and emerging candidate treatments is also presented.

Keywords: Continuous positive airway pressure; Epworth Sleepiness Scale; Hypoxia; Obstructive sleep apnea; Orexin; Residual excessive daytime sleepiness 


\section{Key Summary Points}

Despite optimal treatment of obstructive sleep apnea (OSA) with continuous positive airway pressure, a fair proportion of patients have residual excessive daytime sleepiness (REDS); prevalent globally, REDS remains underdiagnosed and undertreated.

The multifactorial pathophysiologic mechanisms of REDS involve the chronic cyclical hypoxia-reoxygenation effects on dopaminergic and orexinergic neurons, oxidative stress, systemic inflammation, neuronal injury to areas of the brain responsible for maintaining alertness, genetic factors, and sleep fragmentation.

Options for the management of REDS due to OSA include implementing lifestyle changes, ensuring sufficient sleep, addressing the influence of medications with somnogenic effects, effectively treating mood disorders, verifying OSA treatment adherence and effectiveness, evaluating for the existence of other disruptors, and utilizing pharmacologic intervention (when clinically appropriate).

\section{INTRODUCTION}

Recurrent episodes of partial or complete pharyngeal collapse occurring during sleep are the characteristic features of obstructive sleep apnea (OSA) [1], which is defined as an apnea-hypopnea index (AHI) of at least 5 events/h in association with symptoms such as unrefreshing sleep, daytime sleepiness, fatigue or insomnia, awakening with a gasping or choking sensation, loud snoring, or witnessed apneas $[2,3]$. OSA is an established health concern that affects almost 1 billion people globally, with a prevalence that is increasing and can vary widely between countries [4]. The prevalence of moderate-to-severe OSA (defined as at least 15 events/h) is estimated to range from $25 \%$ to $36 \%$ in international-based assessments [4]. Patients with OSA have an increased risk of metabolic and cardiovascular (CV) comorbidities, as well as death $[5,6]$.

Excessive daytime sleepiness (EDS), commonly defined using the standard validated instrument the Epworth Sleepiness Scale (ESS) utilizing a threshold score of greater than 10 [7], is one of the most commonly reported symptoms of OSA, along with fatigue and neurocognitive dysfunction (e.g., compromise in focus and concentration, mood changes that mainly consist of increased irritability) $[1,6]$. EDS is a public health hazard and remains underdiagnosed and undertreated, even in patients who already have a diagnosis of OSA $[8,9]$. EDS in OSA has been shown to be associated with an increased risk of hospitalization and increased outpatient healthcare utilization [8], as well as an increased risk of CV disease [10]. With negative effects not only on the individual but also on social interactions with family members and on a range of workplacerelated factors, EDS can compromise social interactions, diminish cognitive function, impair work productivity and school performance, and result in drowsy driving and decrements in quality of life (QoL) [11-15]. EDS has also been linked to depression, mood disturbances, behavioral challenges, and an increased risk of substance abuse in teenagers $[16,17]$.

First-line treatment of EDS due to OSA is continuous positive airway pressure (CPAP) therapy [7]. CPAP has been demonstrated by meta-analysis to significantly reduce subjective daytime sleepiness (ESS 1.2-point reduction; $95 \%$ confidence interval $[\mathrm{CI}] 0.5-1.9 ; p=0.001$ ) and improve objective daytime wakefulness (Maintenance of Wakefulness Test [MWT] 2.1min improvement; 95\% CI 0.5-3.7; $p=0.011$ ) in patients with mild-to-moderate OSA [18]. However, despite optimal CPAP treatment, some patients have residual EDS (REDS). In a French study $(n=502)$, there was an estimated prevalence of REDS (indicated by an ESS score of at least 11 ) of $12 \%$ among patients with OSA despite adherence to CPAP treatment (i.e., a 
mean usage of $6.1 \pm 1.3 \mathrm{~h} /$ night, which was above the defined threshold for adherence of mean CPAP usage of more than $3 \mathrm{~h} /$ night). After adjustment for potential confounding factors (i.e., depression, restless legs syndrome [RLS], narcolepsy, medications influencing vigilance, suboptimal CPAP treatment), the estimated prevalence of REDS was $6.0 \%$ in patients with OSA who were adherent to CPAP treatment [19]. In other studies that used an ESS score of greater than 10 to indicate REDS, the prevalence of REDS ranged from $15.6 \%$ to $58.3 \%$ in patients with OSA who were adherent to CPAP treatment (i.e., more than $4 \mathrm{~h} /$ night); however, the prevalence of REDS decreased with increasing CPAP usage [1, 20-23].

Challenges remain regarding the evaluation and treatment of patients with REDS due to OSA despite effective adherence to CPAP therapy [7]. Even though primary care physicians are usually the first point of contact for patients with OSA, it is important to know when patients should be referred to a sleep specialist $[9,24,25]$. To help strengthen the knowledge base and advance the understanding of clinicians who typically treat patients with OSA, this narrative review summarizes the pathophysiologic mechanisms involved in EDS due to OSA and the current practices for managing these patients, including the appropriate use of assessment tools, current pharmacologic treatments, and emerging modalities. In addition, confounding factors, such as comorbidities, are discussed and management algorithms are suggested.

This article is based on previously conducted studies and does not contain any new studies with human participants or animals performed by any of the authors.

\section{PATHOPHYSIOLOGIC MECHANISMS OF EDS DUE TO OSA}

The causes and mediators of the pathophysiology of EDS in OSA are multifactorial. Furthermore, the substantial inter-individual variability suggests that dynamic interactions between the mediators of EDS in OSA and the body's repair systems and local damaged tissues are involved. Apnea and hypopnea commonly end with arousal from sleep, which allows the upper airway to reopen and normal breathing to resume. Experimental mouse models that used an intermittent hypoxia intervention implicated cell injury and apoptosis in response to the activation of pathways of inflammation and oxidative stress, resulting in permanent neuronal damage in areas of the brain responsible for the regulation of wake and sleep [26, 27]. These areas of damage were associated with persistence of sleepiness even subsequent to return to the normoxic environment. The repeated arousal-induced sleep fragmentation that occurs in patients with OSA can alter the cyclic structure of sleep [26]. Sleep fragmentation and the hypoxia-reoxygenation cycle may induce inflammation and oxidative stress that may alter the health of wake-activating neurons $[27,28]$. OSA potentially shifts the peak in melatonin secretion [29] and induces fragmented sleep, which may reduce the efficiency of the glymphatic transport system that is proposed to be important for waste removal in the

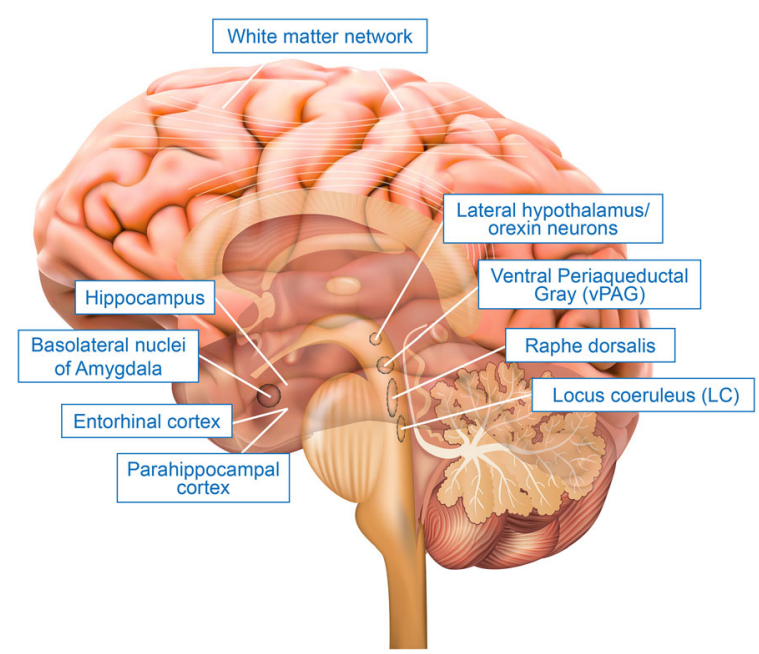

Fig. 1 Gross anatomy showing presumed injured central nervous system regions involved in the generation of residual daytime sleepiness. Brainstem: Wake-promoting neurons: dorsal raphe nucleus, locus coeruleus (LC), and dopamine ventral periaqueductal gray wake neurons (vPAG). Brain: Hippocampus (entorhinal cortex), Amygdala (basolateral nucleus), left posterior parietal cortex, right superior frontal gyrus, and the white matter network (an anatomical substrate crucial for alertness) 
central nervous system during sleep (Fig. 1) [30]. Moreover, a study using diffusion tensor imaging revealed the presence of extensive alterations to white matter in CPAP-treated patients with REDS compared with patients without REDS; some of the alterations correlated with ESS scores [31].

An autopsy study of individuals with OSA showed that those with severe OSA had greater hippocampal atrophy and demyelination than those with mild OSA [32]. Another study based on magnetic resonance imaging (MRI) and polysomnography data demonstrated that OSArelated hypoxemia reduced hippocampus volume (i.e., increased atrophy), which is consistent with previous studies [33]. Individuals who adhered to CPAP therapy in the autopsy study exhibited similar levels of demyelination but showed less atrophy of regions of the hippocampus (i.e., the dentate gyrus, the CA1, and deep layers of the entorhinal cortex) involved in memory pathways compared with individuals who were not known to adhere to CPAP therapy. Patients with OSA often have impaired episodic, spatial, and semantic memory; these impairments may be related to the demyelination and thinner cortical layers in the hippocampus, which is the location of the direct (semantic) and polysynaptic (episodic and spatial) memory pathways that begin in the entorhinal cortex [32]. The potential pathophysiologic mechanisms involved in the development of REDS in OSA are illustrated in Fig. 1 and discussed in more detail below.

\section{Hypoxia and Orexin Pathways}

Inhibition of hypothalamic orexin neuron activity caused by hypoxia and hypercapnia has been implicated as a causal mechanism of EDS in OSA [34, 35]. Rat studies have shown that acute hypoxia/hypercapnia rapidly inactivates orexin neurons, which may contribute to impaired function of orexin neurons in individuals with OSA [34]. Orexins are neuropeptides that play an important role in sleep-wake cycle regulation, helping to maintain both waking state and rapid eye movement (REM) sleep [36-39]. Reduced orexin neuron activity and neurotransmission have been implicated in sleep disorders, including OSA. Also, downregulated plasma levels of orexin-A have been demonstrated in patients with OSA [34].

There is also evidence that orexin contributes to respiratory regulation [36, 40, 41]. Orexin-A can activate expression of hypoxiainducible factor $1 \alpha$ (HIF- $1 \alpha$ ), a transcription factor with a role in ischemia and hypoxia [38], as well as downstream targets of HIF- $1 \alpha$, such as vascular endothelial growth factor and erythropoietin [42]. Increases in orexin-A may also be involved in OSA-associated neurocognitive deficits, such as spatial memory and learning deficits. In a hypoxia model in cultured rat hippocampal neurons, orexin-A increased intermittent hypoxemia-induced hippocampal neuronal damage by overphosphorylation of extracellular signal-regulated kinase $1 / 2$ through the orexin receptor-phospholipase C$\beta 1$ (PLC $\beta 1$ ) pathway [43]. In addition, chronic exposure to hypoxia/hypercapnia has been shown to compromise neurotransmission from orexin neurons to parasympathetic cardiac vagal neurons [37, 44, 45]. Results from these rat studies suggest that exaggerated inhibitory neurotransmission from the lateral paragigantocellular nucleus to cardiac vagal neurons may lead to a sleep-associated high risk of tachycardia, arrhythmia, and sudden cardiac death in people with OSA [44].

\section{Oxidative Stress and Inflammation}

Intermittent hypoxia exposure led to augmented oxidative stress and elevated inflammatory mediators in rodent animal models, which correlated with injury to wake-promoting neurons and supportive brain cells $[26,46]$. For example, after mice were exposed to longterm intermittent hypoxia (LTIH) for 8 weeks, total daily sleep time and non-REM sleep were each lengthened by more than $2 \mathrm{~h}$ (an approximately $33 \%$ increase) upon return to normal oxygenation in LTIH-exposed mice compared with sham-treated mice. The wake-promoting regions of the basal forebrain and brainstem provided abnormal polysomnographic findings, and oxidative-injury measures were suggestive 
of oxidative stress and injury. After LTIH cessation, the LTIH-exposed mice also had significantly reduced mean sleep latency compared with sham-treated mice [26]. Another study demonstrated that even 6 months after an 8-week exposure to hypoxia-reoxygenation, irreversible injury was evident in the noradrenergic neurons in the locus coeruleus and the dopaminergic neurons in the periaqueductal gray area. Further, chronic sleep deprivation induced a significant $25 \%$ reduction $(p<0.05)$ in orexinergic neurons compared with control mice [47]. Taken together, these data suggest that hypoxia-reoxygenation and chronic sleep deprivation can lead to the injury of multiple brain regions.

Inflammation induced by cycles of hypoxia-reoxygenation is considered one of the key underlying mechanisms of sleep-disordered breathing and EDS [7, 27]. Inflammatory cytokines (e.g., interleukin [IL]-6, IL-8, tumor necrosis factor- $\alpha$ ) are often monitored as indicators of the inflammatory cascade. In patients with systolic heart failure, the inflammatory markers cortisol and IL-6 have been significantly associated with mean sleep latency (an objective measure of sleepiness) but not with ESS (a subjective measure of sleepiness) [48]. Since subjective and objective measures of sleepiness do not always correlate [49], these data further support the possibility that underlying mechanisms may overlap but may also involve distinct mediators [48]. Other studies, including the prospective study by Chen et al., have suggested possible interactions between systemic inflammation and microstructural damage in the brain due to OSA-related hypoxia [50].

\section{Other Potential Mechanisms}

Sleep fragmentation, a common consequence of OSA, may alter the efficiency of the glymphatic system. Rodent animal models were used to describe the glymphatic system, which is responsible for the efficient removal of waste from the brain during sleep. This paravascular cerebrospinal fluid transport system was twofold more efficient in removing waste (i.e., amyloid- $\beta$ ) during the slow-wave cycle in sleeping mice compared with awake mice $[30,51]$. The possibility of an analogous transport system in human brains was explored using brain imaging with MRI in healthy participants during different sleep-wake phases. In this study, sleep-induced increases in cerebrospinal fluid volume in the whole human brain were observed, which supports the possibility of a paravascular glymphatic system in humans that may function to remove waste from the brain during sleep. Interestingly, this MRI study showed that several different brain regions, particularly the cerebellum, experienced diffusion changes at different phases of the sleep-wake cycle, suggesting a more complex rhythm in humans than in rodents [52]. Further research is needed to determine whether alterations in slow-wave sleep patterns in patients with OSA [28] cause changes in brain accelerated diffusion dynamics or the efficiency of waste removal.

A study showed an altered circadian rhythm of melatonin secretion in about $25 \%$ of patients with OSA ( $n=18)$ and significantly lower peak melatonin levels in those with a preserved circadian rhythm of melatonin secretion compared with healthy participants [29]. Although evidence is limited, it may be interesting to investigate whether melatonin supplementation aids sleep efficiency and improves REDS in patients with OSA.

Dysbiosis has also been associated with OSA, with the richness and diversity of the microbiome of male individuals $(n=22$; without a history of gastrointestinal illness or prior use of pharmaceuticals) being positively correlated with total sleep time (assessed by actigraphy over a 4-week period) [53]. Additionally, in a rat model of OSA, a high-fat diet led to hypertension within 7 days of OSA, with continued blood pressure increases at 14 days; the gut microbiota concurrently harbored fewer taxa that produce the short-chain fatty acid butyrate. Fecal transplants from hypertensive rats with OSA on a high-fat diet to normotensive rats with OSA on a normal diet led to induced hypertension within 7 days of OSA, with blood pressure increases continuing at 14 days [54]. Taken together, these data raise the possibility 
that specific genera in the nasal glands, salivary glands, and gut microbiomes of humans, coupled with lifestyle choices, may increase the risk for OSA, EDS, and hypertension.

\section{Genetic Factors}

Genetic factors may provide a higher risk for EDS in some populations. In the Multi-Ethnic Study of Atherosclerosis Sleep Cohort $(n=2230)$, EDS (according to an ESS score of greater than 10) was most prevalent in Blacks/ African Americans (18.8\%) and Hispanic Americans $(13.6 \%)$ and least prevalent in White Americans (11.4\%) and Chinese Americans (11.1\%). Furthermore, Blacks/African Americans had a significantly higher risk of EDS (odds ratio 1.89) and sleep apnea (odds ratio 1.78) compared with White Americans after adjustment for sex, age, and study site [55]. Moreover, an epigenome-wide association analysis of the Multi-Ethnic Study of Atherosclerosis Sleep Cohort revealed that one locus was associated with EDS in all ethnic groups (i.e., Blacks/African Americans, White Americans, and Hispanic Americans), and three additional loci were associated with EDS in Blacks/African Americans [56]. These results may help explain the higher risk for objective and subjective sleepiness detected in the African-American population despite adjusting for numerous confounding factors by multivariate analysis [57].

\section{THE SLEEPY OSA PHENOTYPE AND INCREASED CV RISK}

On the basis of clinical symptoms, a sleepy OSA phenotype has been characterized and is distinct from other subtypes of OSA, such as those with disturbed sleep symptoms and those with a relative lack of traditional OSA symptoms. Furthermore, the sleepy OSA phenotype has been associated with an increased risk of adverse CV outcomes, such as heart failure and coronary heart disease [10]. Given the increased CV risk observed in patients with EDS in OSA [10] and reported treatment benefits in $\mathrm{CV}$ outcomes (i.e., blood pressure), especially in sleepy (i.e., greater EDS and/or more severe OSA) versus non-sleepy OSA phenotypes $[58,59]$, it is important that these patients receive adequate treatment. However, the Impact of Sleep Apnea Syndrome in the Evolution of Acute Coronary Syndrome: Effect of Intervention With CPAP (ISAACC) trial, a secondary prevention trial designed to evaluate the effect of OSA and the effectiveness of CPAP treatment on the clinical evolution and prognosis of patients with acute coronary syndrome, found that CPAP had no positive effect on the prevention of recurrent $\mathrm{CV}$ events in patients with OSA and acute coronary syndrome compared with usual care alone $[60,61]$. However excessively sleepy patients were excluded from this trial.

\section{MANAGEMENT OF REDS DUE TO OSA}

Multiple perspectives encompassing a patient's comorbidities, health status, impact on daily living, and profession can help inform decisions regarding referral to a sleep specialist. Depending on the ESS score and clinical judgment, primary care physicians may consider referring their patients to a sleep specialist (Fig. 2). Since REDS, despite the apparent adherence to CPAP treatment, could be due to the presence of other treatable conditions, such comorbidities should be systematically ruled out. Some potentially treatable causes of REDS due to OSA (e.g., inadequate CPAP treatment, comorbidities, insufficient sleep due to other causes) are shown in Table 1 and discussed in more detail below [7]. Whenever possible, the priorities for the management of REDS due to OSA, before initiating pharmacologic intervention, are as follows: adjusting medications for comorbid conditions to those with less sedative effects, adjusting CPAP for optimal treatment effect, evaluating alternative PAP treatments such as oral appliance or hypoglossal nerve stimulation, ensuring sufficient sleep, identifying and treating depression, performing an assessment for other hypersomnia disorders such as narcolepsy, and establishing lifestyle changes are considered priorities for the treatment of EDS 


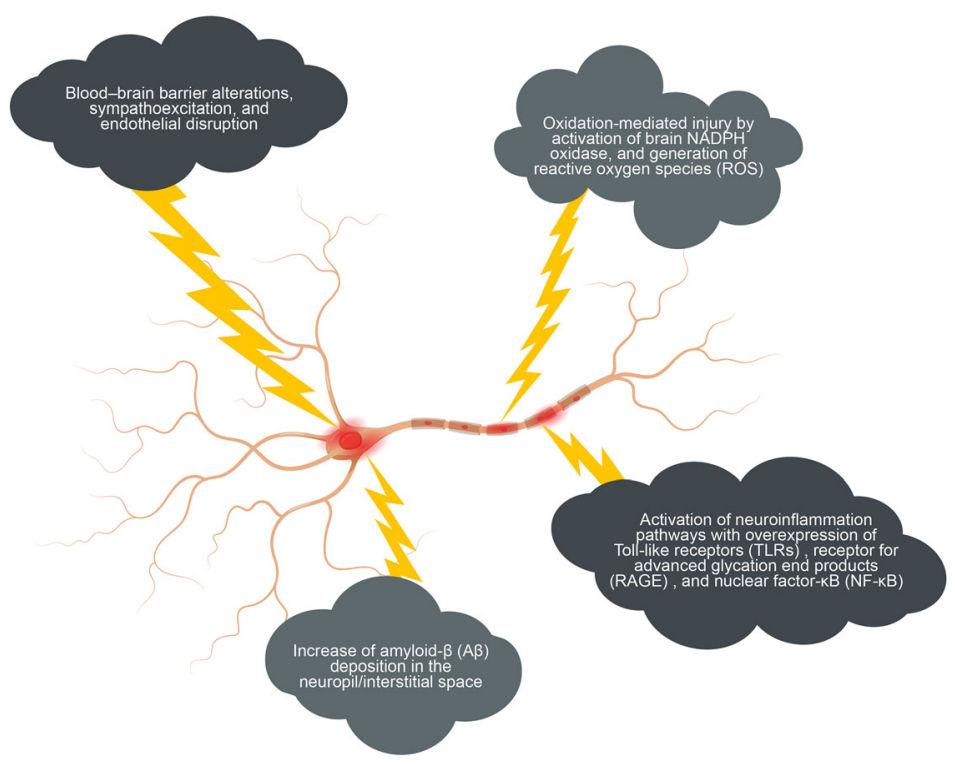

Fig. 2 Insights into the molecular mechanisms underlying residual daytime sleepiness: intermittent hypoxia (IH) and slow wave sleep (SWS) disruption, may induce alterations in the neuronal microenvironment

Table 1 Potentially treatable causes of EDS due to OSA [7]

\begin{tabular}{lll}
\hline Insufficient sleep & Comorbidities & Inadequate CPAP treatment \\
\hline - Behavior induced & $\bullet$ Anxiety or depression & $\bullet$ Insufficient usage \\
- Shift work leading to circadian rhythm & $\bullet$ Hypothyroidism & $\bullet$ Excessive mask leak \\
disorders & $\bullet$ Narcolepsy & $\bullet$ Suboptimal pressure \\
- Insomnia & $\bullet$ Obesity & $\bullet$ Treatment-emergent central sleep \\
& $\bullet$ Restless legs syndrome & \\
& $\bullet$ Rapid eye movement-predominant & \\
& OSA & \\
& $\bullet$ Somnogenic medications
\end{tabular}

Adapted with permission from Javaheri and Javaheri [7]

$C P A P$ continuous positive airway pressure, $E D S$ excessive daytime sleepiness, $O S A$ obstructive sleep apnea

due to OSA before initiating pharmacologic intervention.

\section{Comorbid Conditions}

Patients with OSA often have comorbidities that may obscure the diagnosis of EDS. Moreover, patients with OSA and EDS have been shown to have more comorbid symptoms than those without EDS [62]. Known comorbid conditions of OSA include obesity, depression, anxiety, RLS, periodic leg movements, narcolepsy, and circadian rhythm disorders [7, 62-67]. Screening of patients with REDS using the Beck Depression Inventory-II questionnaire, for 
example, could help to exclude the presence of comorbid depression [68]. Also, screening for coexisting circadian rhythm disorders that may contribute to REDS is warranted, especially in commercial drivers and pilots [7]. Since sleep problems, such as OSA and EDS, have been associated with the current coronavirus disease 2019 (COVID-19) pandemic [69, 70], postCOVID-19 fatigue should be ruled out as well. Also, treatment-emergent central sleep apnea should be considered as a cause of persistent sleepiness since it can develop during treatment of OSA with CPAP and is also associated with EDS [71].

It is important to note that many of the aforementioned comorbid conditions may be treated using medications with somnolence-inducing adverse effects. Thus, a patient's medications should be examined to identify those that can induce drowsiness or sleepiness [7, 72]. Since some medications prescribed to treat depression (e.g., imipramine [an activating tricyclic antidepressant]) or anxiety (e.g., benzodiazepines) may augment the tendency toward sleepiness, medication adjustments may be needed to reduce this potential adverse effect [7, 72-74]. Among antidepressants, imipramine, doxepin, and amitriptyline are a few agents that are likely to cause sleepiness [73]. Sleepiness is also one of the associated side effects of dopaminergic agonists, which are often used to treat RLS and periodic limb movements in sleep $[7,75-77]$. Other medications that can induce drowsiness include antihistamines (e.g., meclizine, hydroxyzine, diphenhydramine [Benadryl $\left.{ }^{\circledR}\right]$ ); antihypertensive medications (e.g., beta-blockers), which often decrease the heart rate; muscle relaxants (e.g., carisoprodol, cyclobenzaprine), which often mediate effects on the brain; and opioid analgesics $[7,73,78-80]$. The combination of opioids with acetaminophen can disrupt sleep by causing increased awakenings, decreased slow-wave sleep, and suppressed REM sleep [73].

\section{Optimizing Current Treatment}

As an initial step, it is important to ensure that current treatment is optimized. For example, the data of the CPAP device should be interrogated for its pattern of use, assessed for an excessive leak, and evaluated to ascertain the residual AHI of a patient. If it is obvious from these data that a patient's current treatment is not optimal, the physician should make appropriate adjustments. Adjustment of the CPAP apparatus for comfortable and effective nightly use may help improve airflow and treatment adherence. In some cases, lifestyle changes may expand the benefits of CPAP treatment sufficiently to improve a patient's QoL. For example, physical exercise combined with CPAP treatment has been demonstrated to improve QoL and subjective EDS [81].

Alternative airway-directed therapies, such as positional therapy, mandibular advancement devices (MADs), or hypoglossal nerve stimulation are typically offered to patients who decline or do not tolerate CPAP and may also be useful in patients with REDS due to OSA despite CPAP adherence. The use of MADs has been associated with an improvement of symptoms in patients with mild-to-moderate OSA [49, 82], and MADs may have a higher rate of adherence than CPAP [83]. As part of an individualized treatment plan, ablative surgery options, such as tonsillectomy, maxillomandibular osteotomy, or bariatric surgery for extreme obesity, may be suitable for selected patients with OSA and REDS [49].

Various risk factors are reportedly associated with REDS after CPAP. A French study in 1047 patients with OSA treated with CPAP for more than $3 \mathrm{~h}$ /day showed that high baseline degree of OSA (defined by the AHI) and depression were independent predictors of REDS. Patients with REDS also were more likely to be female and had generally worse health [1]. Other reported risk factors of REDS include a high pretreatment ESS score, age less than 55 years, and a history of diabetes and heart disease $[19,21,23]$. REDS has also been associated with upper airway resistance syndrome (UARS) [84]. UARS affects proportionately more women than men and is characterized by a narrowing of the posterior airway space behind the base of the tongue $[84,85]$. When left untreated, UARS can negatively affect QoL and has CV and metabolic consequences; thus, it is important to rule out 
Table 2 Subjective assessment tools for determining the risk of EDS

\begin{tabular}{|c|c|c|c|c|}
\hline Tool & Measure & Description & Interpretation & $\begin{array}{l}\text { Completion } \\
\text { time, min }\end{array}$ \\
\hline $\begin{array}{l}\text { ESS } \\
\qquad[86,90]\end{array}$ & $\begin{array}{l}\text { Propensity for } \\
\text { daytime } \\
\text { sleepiness }\end{array}$ & $\begin{array}{l}8 \text { items; self-rated; each item scored } \\
0-3\end{array}$ & $>10$ indicates EDS & 5 \\
\hline FAS [111] & $\begin{array}{l}\text { Propensity for } \\
\text { fatigue }\end{array}$ & $\begin{array}{l}10 \text { items; self-rated; each item } \\
\text { scored } 1-5\end{array}$ & $\begin{array}{l}\text { Range } 10-50 ; 10 \text { is lowest, } 50 \text { is } \\
\text { highest }\end{array}$ & 2 \\
\hline FSS [112] & $\begin{array}{l}\text { Severity and } \\
\text { impact of fatigue }\end{array}$ & $\begin{array}{l}9 \text { items; self-rated; each item scored } \\
1 \text { (strongly disagree) to } 7 \\
\text { (strongly agree) }\end{array}$ & $\begin{array}{l}\text { A higher score indicates more } \\
\text { severe fatigue }\end{array}$ & \\
\hline $\begin{array}{r}\text { PHQ-9 } \\
{[113]}\end{array}$ & $\begin{array}{l}\text { Frequency of } \\
\text { depression } \\
\text { symptoms }\end{array}$ & $\begin{array}{l}9 \text { items; self-rated; item \#3 relates } \\
\text { to sleep }\end{array}$ & $\begin{array}{l}\text { Range } 0 \text { (not at all) to } 3 \text { (nearly } \\
\text { every day) }\end{array}$ & \\
\hline $\begin{array}{l}\text { PROMIS } \\
\quad[90]\end{array}$ & $\begin{array}{l}\text { Sleep quality, } \\
\text { depth, and } \\
\text { satisfaction }\end{array}$ & 27 items; self-rated & $\begin{array}{l}\text { A higher score indicates more } \\
\text { sleep disturbance }\end{array}$ & $10-15$ \\
\hline $\begin{array}{l}\text { PROMIS-8 } \\
\quad[90]\end{array}$ & $\begin{array}{l}\text { Sleep quality, } \\
\text { depth, and } \\
\text { satisfaction }\end{array}$ & 8 items; self-rated & $\begin{array}{l}\text { A higher score indicates more } \\
\text { sleep disturbance }\end{array}$ & 5 \\
\hline $\begin{array}{l}\text { FOSQ-30 } \\
{[90]}\end{array}$ & $\begin{array}{l}\text { Impact of EDS on } \\
\text { ADL and QoL }\end{array}$ & $\begin{array}{l}30 \text { items; self-rated; each item } \\
\text { scored } 1-4\end{array}$ & $\begin{array}{l}\text { A higher score indicates less } \\
\text { impact on function }\end{array}$ & 15 \\
\hline $\begin{array}{c}\text { FOSQ-10 } \\
{[90]}\end{array}$ & $\begin{array}{l}\text { Impact of EDS on } \\
\mathrm{ADL} \text { and QoL }\end{array}$ & $\begin{array}{l}\text { Short form } 10 \text { items; self-rated; } \\
\text { each item scored } 1-4\end{array}$ & $\begin{array}{l}\text { A higher score indicates less } \\
\text { impact on function }\end{array}$ & $5-7$ \\
\hline PSQI [90] & $\begin{array}{l}\text { Sleep quality and } \\
\text { habits during } \\
\text { the previous } \\
\text { month }\end{array}$ & $\begin{array}{l}19 \text { items; self-rated and bed- } \\
\text { partner-rated ( } 5 \text { items) }\end{array}$ & $\begin{array}{l}\text { Sum of } 7 \text { domain scores (range } \\
0-21 \text { ); a score }>5 \text { indicates } \\
\text { poor quality sleep }\end{array}$ & $5-10$ \\
\hline $\begin{array}{c}\text { BDI-II } \\
{[68]}\end{array}$ & $\begin{array}{l}\text { Severity of } \\
\text { depression }\end{array}$ & $\begin{array}{l}21 \text { items; self-rated to capture } \\
\text { cognitive, affective, somatic, and } \\
\text { vegetative symptoms; 4-point } \\
\text { scale from } 0 \text { (absent) to } 3 \\
\text { (severe) }\end{array}$ & $\begin{array}{l}\text { Range } 0-63 \text {, with scores of } 14-19 \text {, } \\
20-28, \text { and } 29-63 \text { indicating } \\
\text { mild, moderate, and severe } \\
\text { impairment, respectively }\end{array}$ & $5-10$ \\
\hline $\begin{array}{l}\text { BDI-FS } \\
\qquad[68,114]\end{array}$ & & $\begin{array}{l}7 \text { items; self-rated; short version for } \\
\text { family physicians }\end{array}$ & $\begin{array}{l}\text { Range } 0-21 \text {, with scores of } 4-8 \text {, } \\
\text { 9-12, or } 13-21 \text { indicating mild, } \\
\text { moderate, or severe impairment, } \\
\text { respectively }\end{array}$ & $<5$ \\
\hline
\end{tabular}


Table 2 continued

\begin{tabular}{|c|c|c|c|c|}
\hline Tool & Measure & Description & Interpretation & $\begin{array}{l}\text { Completion } \\
\text { time, min }\end{array}$ \\
\hline $\begin{array}{l}\text { CES-D } \\
{[115]}\end{array}$ & $\begin{array}{l}\text { Frequency of } \\
\text { depression- } \\
\text { associated } \\
\text { symptoms (e.g., } \\
\text { restless sleep) }\end{array}$ & $\begin{array}{l}20 \text { items; self-rated; each item rated } \\
\text { from } 0 \text { (rarely) to } 3 \text { (most of } \\
\text { almost all the time) }\end{array}$ & $\begin{array}{c}\text { Range } 0-60, \text { high scores indicate } \\
\text { more symptoms of depression }\end{array}$ & \\
\hline
\end{tabular}

At minimum, the ESS and BDI should be used for screening patients, but further evaluation may require screening with the other tools listed

$A D L$ activities of daily living, BDI-FS Beck Depression Inventory-Fast Screen, BDI-II Beck Depression Inventory-Second Edition, CES-D Center for Epidemiological Studies-Depression, EDS excessive daytime sleepiness, ESS Epworth Sleepiness Scale, FAS Fatigue Assessment Scale, FOSQ Functional Outcomes of Sleep Questionnaire, FSS Fatigue Severity Scale, PHQ9 Patient Health Questionnaire-9, PROMIS Patient-Reported Outcomes Measurement Information System, PROMIS-8 Patient-Reported Outcomes Measurement Information System (8 items), PSQI Pittsburgh Sleep Quality Index, QoL quality of life

UARS as a cause of REDS. Polysomnographic studies can be used to distinguish UARS from OSA [84].

\section{Subjective Versus Objective Assessment of REDS}

There are many subjective (Table 2) and objective (Table 3) clinical tools available for the assessment of REDS. Subjective measures are an efficient and cost-effective way of estimating EDS. Completion of a sleep diary by a patient for 2 weeks could provide useful information. Also, the ESS is a commonly used subjective questionnaire that captures a patient's self-reported likelihood of falling asleep on a scale of 0 (never) to 3 (high chance of dozing) under eight different everyday scenarios [86]. Validation in a large clinical sample demonstrated that the ESS provides an accurate measure of daytime sleepiness that is interpreted similarly across all patients [87], and item-response theory analyses confirmed the reliability of the ESS as a measure of the propensity to sleepiness [88]. ESS scores range from 0 to 24, with EDS often defined as a score of greater than 10, and EDS severity is categorized according to ESS scores of 11 to less than 15 (mild), 15 to less than 18 (moderate), or 18 to 24 (severe) [89]. To minimize completion times, shortened versions of some self-reported questionnaires may be used where available. Time to completion is about $5 \mathrm{~min}$ for ESS, so it can easily be completed during an office visit [90]. Digital integration in subjective reporting instruments also assists in enhancing the efficiency of data collection and allows for the ability to follow trends in response to treatment interventions.

However, subjective measures of sleepiness as a sole test may be unreliable in some clinical situations [13]. For example, known adaptation of a patient's perception toward chronic sleep deprivation may cause discrepancies between subjective sleep quality and objective assessments of sleep (i.e., either a poorer perception of sleep vs. objective measurement or perceived good sleep when there is objective sleep disruption) [91]. The ability to disregard symptoms of sleepiness helps to explain why EDS remains underdiagnosed and underreported, as well as the poor correlation observed between ESS scores and AHI or objective measurements (such as the Multiple Sleep Latency Test [MSLT]) [49]. Indeed, a dissociation between self-reported EDS and objective sleepiness has been noted in patients with OSA and heart failure, with some patients having a mean sleep latency of $5 \mathrm{~min}$ or less despite normal ESS scores and biomarkers 
Table 3 Objective assessment tools for determining the risk of EDS

\begin{tabular}{|c|c|c|c|c|}
\hline Tool & Description & Measure & Interpretation & Time \\
\hline $\begin{array}{l}\text { Actigraphy (as } \\
\text { an objective } \\
\text { supplement } \\
\text { to sleep } \\
\text { diary) }[90]\end{array}$ & $\begin{array}{l}\text { Wristwatch-sized instrument } \\
\text { that captures amplitude of } \\
\text { movement over time that } \\
\text { distinguishes sleeping } \\
\text { versus wakeful activity in } \\
\text { "home" scenarios }\end{array}$ & $\begin{array}{l}\text { Sleep-wake patterns, } \\
\text { including total wake time, } \\
\text { total sleep time, efficiency, } \\
\text { latency, number and length } \\
\text { of arousal periods in } \\
30-60-\text { s intervals }\end{array}$ & $\begin{array}{l}\text { Reader download and } \\
\text { computer analysis of } \\
\text { movement patterns over a } \\
\text { 24-h period, especially } \\
\text { reliable if worn for } \\
\text { 7-14 days }\end{array}$ & $7-14$ days \\
\hline $\begin{array}{l}\text { MSLT } \\
\qquad[90,116]\end{array}$ & $\begin{array}{l}\text { Tendency or ability to fall } \\
\text { asleep during daytime in- } \\
\text { laboratory PSG }\end{array}$ & $\begin{array}{l}\text { Excessive sleepiness, } \\
\text { idiopathic hypersomnia, } \\
\text { and narcolepsy; not used } \\
\text { routinely for medical or } \\
\text { neurological sleepiness }\end{array}$ & $\begin{array}{l}<5 \text { min indicates excessively } \\
\text { sleepy (normal, } \\
10-20 \text { min) }\end{array}$ & $8 \mathrm{~h}$ \\
\hline MWT [116] & $\begin{array}{l}\text { Ability to remain awake in a } \\
\text { dark, quiet environment }\end{array}$ & $\begin{array}{l}\text { Sleep latency in } 20 \text { - or } \\
40 \text {-min MWT test, } 4 \text { or } 5 \\
\text { trials, spaced } 2 \mathrm{~h} \text { apart }\end{array}$ & $\begin{array}{l}\text { Normal } 11-20 \mathrm{~min} \text {; cutoff } \\
\text { value usually }<12 \mathrm{~min}\end{array}$ & $8 \mathrm{~h}$ \\
\hline $\begin{array}{l}\text { In-laboratory } \\
\text { PSG [90] }\end{array}$ & $\begin{array}{l}\text { Uses PSG, recording devices } \\
\text { and monitors; "gold } \\
\text { standard" for evaluation of } \\
\text { sleep }\end{array}$ & $\begin{array}{l}\text { Sleep architecture and } \\
\text { characteristics; diagnosis of } \\
\text { OSA, etc.; titration of } \\
\text { positive airway pressure }\end{array}$ & $\begin{array}{l}\text { Determines sleep stages, } \\
\text { duration, efficiency, sleep } \\
\text { latency, arousals, REM } \\
\text { sleep latency }\end{array}$ & Overnight \\
\hline $\begin{array}{r}\text { In-home sleep } \\
\text { testing [90] }\end{array}$ & $\begin{array}{l}\text { PSG, unattended, sleep } \\
\text { technician or patient with } \\
\text { training set up } \\
\text { portable PSG, monitors in } \\
\text { home environment }\end{array}$ & $\begin{array}{l}\text { Sleep architecture and } \\
\text { characteristics; diagnosis of } \\
\text { OSA (with high } \\
\text { probability of moderate-to- } \\
\text { severe OSA); titration of } \\
\text { positive airway pressure }\end{array}$ & $\begin{array}{l}\text { Dependent on SCOPER } \\
\text { channels; determines sleep } \\
\text { stages, duration, efficiency, } \\
\text { sleep latency, arousals, } \\
\text { REM sleep latency [117] }\end{array}$ & $\begin{array}{l}\text { At least } \\
\text { overnight }\end{array}$ \\
\hline
\end{tabular}

$E D S$ excessive daytime sleepiness, MSLT Multiple Sleep Latency Test, $M W T$ Maintenance of Wakefulness Test, OSA obstructive sleep apnea, PSG polysomnography, REM rapid eye movement, SCOPER Sleep Cardiovascular Oximetry Position Effort and Respiratory

of systemic inflammation being more closely associated with objective rather than subjective measures of sleepiness [48].

The extent of REDS and its impact on a patient with OSA may be more accurately measured with input on the ESS from a partner or with the addition of focused questions from the physician [13, 49]. Additionally, in the context of the clinical history of a patient, whenever possible, results of subjective measures should be confirmed with objective measures (Table 3), especially when a patient has a high-risk occupation (e.g., commercial driver, pilot) $[13,49,92]$. Use of actigraphy may help to exclude other sleep disorders (e.g., compartmental sleep deprivation, "insufficient sleep syndrome") as potential reasons for REDS. Many of these assessments are only available at specialist sleep centers; thus, referral to a sleep specialist may be required. It would also make sense to perform an objective assessment of sleepiness (e.g., MSLT, MWT) before considering additional medications for patients with REDS, although these tests are currently not a requirement in all countries [92]. Laboratorybased objective measures of sleepiness and 
wakefulness include the MSLT (a validated objective measure of the ability or tendency to fall asleep) and the MWT (a validated objective measure of the ability to stay awake for a defined time) $[92,93]$. The MSLT is indicated in patients with suspected narcolepsy to confirm the diagnosis and may be used to help differentiate idiopathic hypersomnia from narcolepsy. The MWT may be used to assess an individual's ability to remain awake when his or her inability to remain awake constitutes a public or personal safety issue (i.e., in individuals with OSA, narcolepsy, or other sleep disorders who are employed in occupations involving public transportation or safety that may require assessment of their ability to remain awake). While the MWT may be used to assess response to treatment in patients with excessive sleepiness, the MSLT is not routinely used in this indication [92].

\section{Currently Approved Pharmacologic Interventions}

In addition to airway-focused therapy, wakepromoting medications have a core adjunctive role in improving REDS in patients with OSA. Wake-promoting medications have been shown to improve REDS (Table 4); however, their prescription in many countries is limited to specialist physicians only. In addition, because of adverse $\mathrm{CV}$ effects seen with some agents, a pretreatment electrocardiogram and/or input from a cardiologist is required in some countries. Nevertheless, there are no guidelines regarding $\mathrm{CV}$ recommendations prior to prescription of wake-promoting medications.

Table 4 outlines the efficacy, safety, and CV tolerability of currently available medications for REDS. While modafinil/armodafinil is approved in the USA [94, 95] and was initially approved in Europe, the European Medicines Agency advised physicians in 2010 to no longer prescribe modafinil for the treatment of excessive sleepiness associated with OSA, idiopathic hypersomnia, and chronic shift work sleep disorder because of concerns about risks of neuropsychiatric disorders and particular CV risks in patients with cardiac arrhythmias and uncontrolled hypertension [96]. Lower CV risk has been observed with solriamfetol and particularly with pitolisant $\left(\mathrm{H}_{3}\right.$ receptor antagonist/inverse agonist) than has been observed with modafinil (Table 4) [97-100]. Solriamfetol is approved for the treatment of EDS in OSA in the USA and in Europe [98, 101-103]. In addition, pitolisant has been studied for EDS in OSA in the USA and in Europe [97, 104, 105]; it is approved in the USA for the treatment of EDS in narcolepsy [106] and in Europe for the treatment of EDS in OSA [107, 108]. In light of observed adverse CV effects with solriamfetol, periodic monitoring of vital signs is suggested (e.g., every 6 months initially or yearly) [101]. Also, concurrent use of solriamfetol with a monoamine oxidase inhibitor is contraindicated because of the increased risk of hypertensive reactions [101], and concurrent use of pitolisant with drugs that may prolong QT interval should be avoided [106].

\section{Emerging Therapies for EDS Due to OSA}

TAK-925 is a hypocretin/orexin-2 receptor-selective agonist that is currently under clinical development for EDS [109]. A phase 1 randomized, double-blind, placebo-controlled, crossover clinical trial investigating the safety and pharmacokinetics of TAK-925 in 25 patients with EDS due to OSA despite adequate use of CPAP was completed in April 2020. TAK-925 was administered as an infusion, and drug concentrations in the blood were determined at multiple time points during infusion (up to $9 \mathrm{~h}$ ) and afterwards (up to $15 \mathrm{~h}$ ). The primary outcome was the safety profile of TAK-925 (treatment-emergent adverse events, abnormal clinical safety laboratory tests, vital signs, and 12-lead electrocardiogram parameters), and secondary outcomes included pharmacokinetics and pharmacodynamics [110]. Results have not yet been published [110] but are awaited with interest. TAK-925 is also being investigated for the treatment of EDS in patients with narcolepsy. Other compounds are being investigated for treatment of EDS in narcolepsy, including FT218, JZP-258, AXS-12, THN102, 


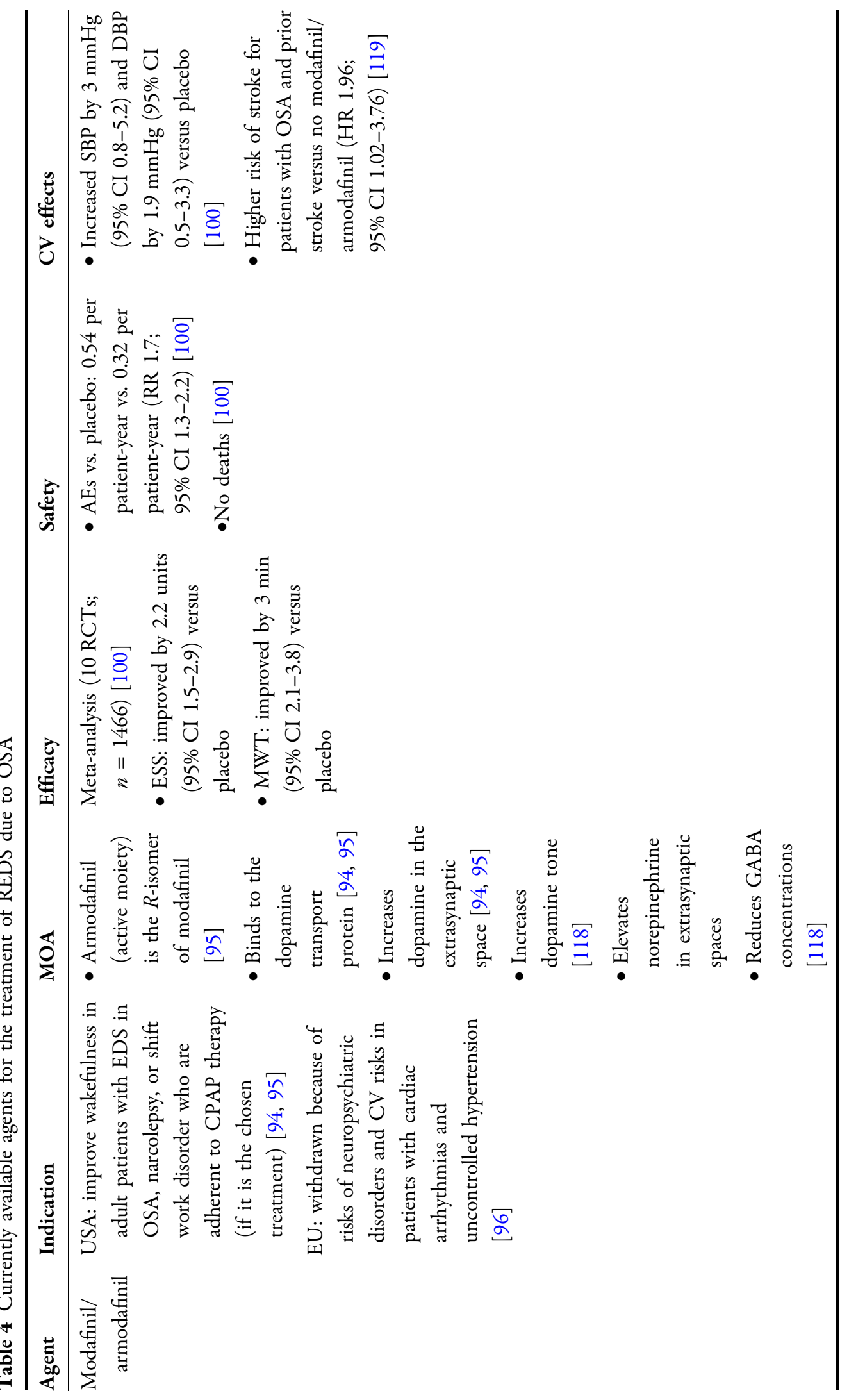




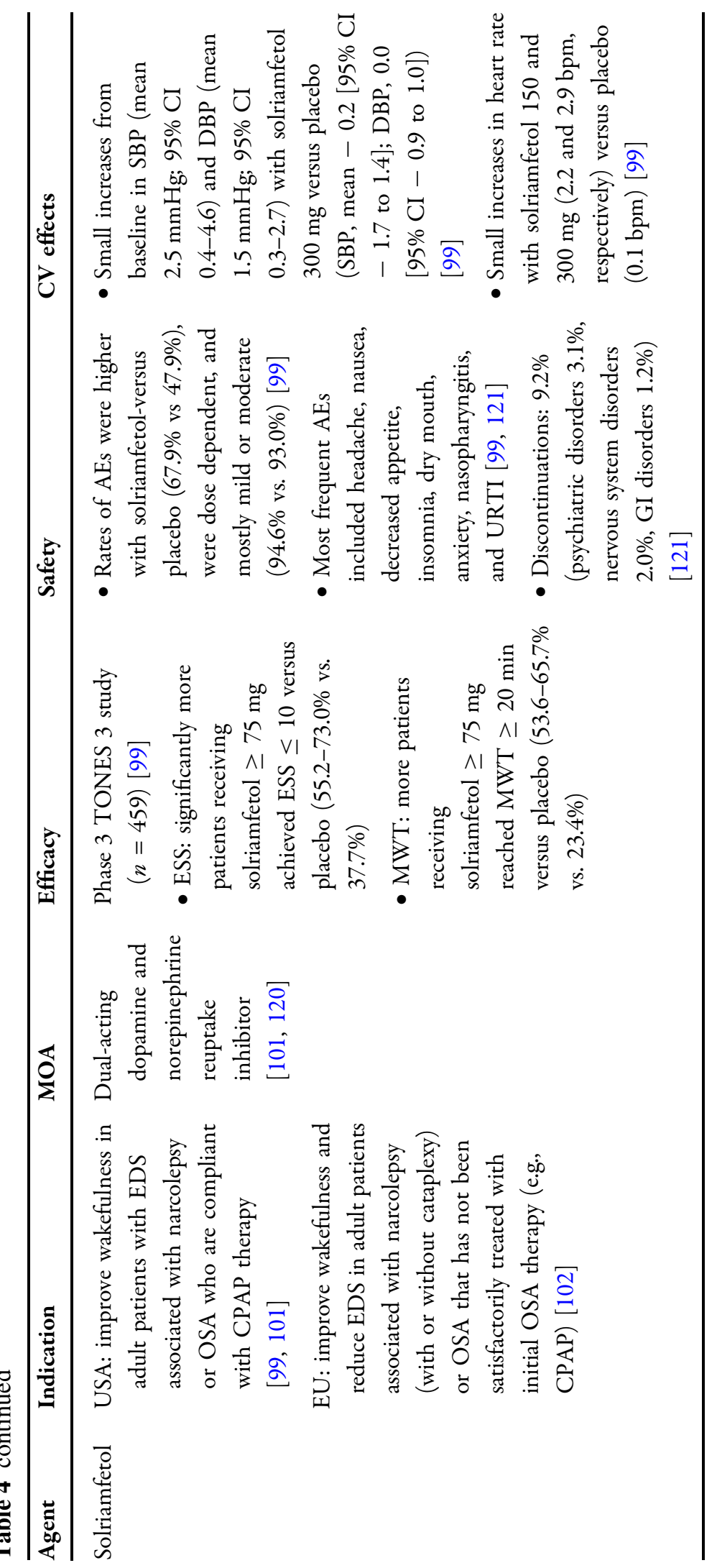




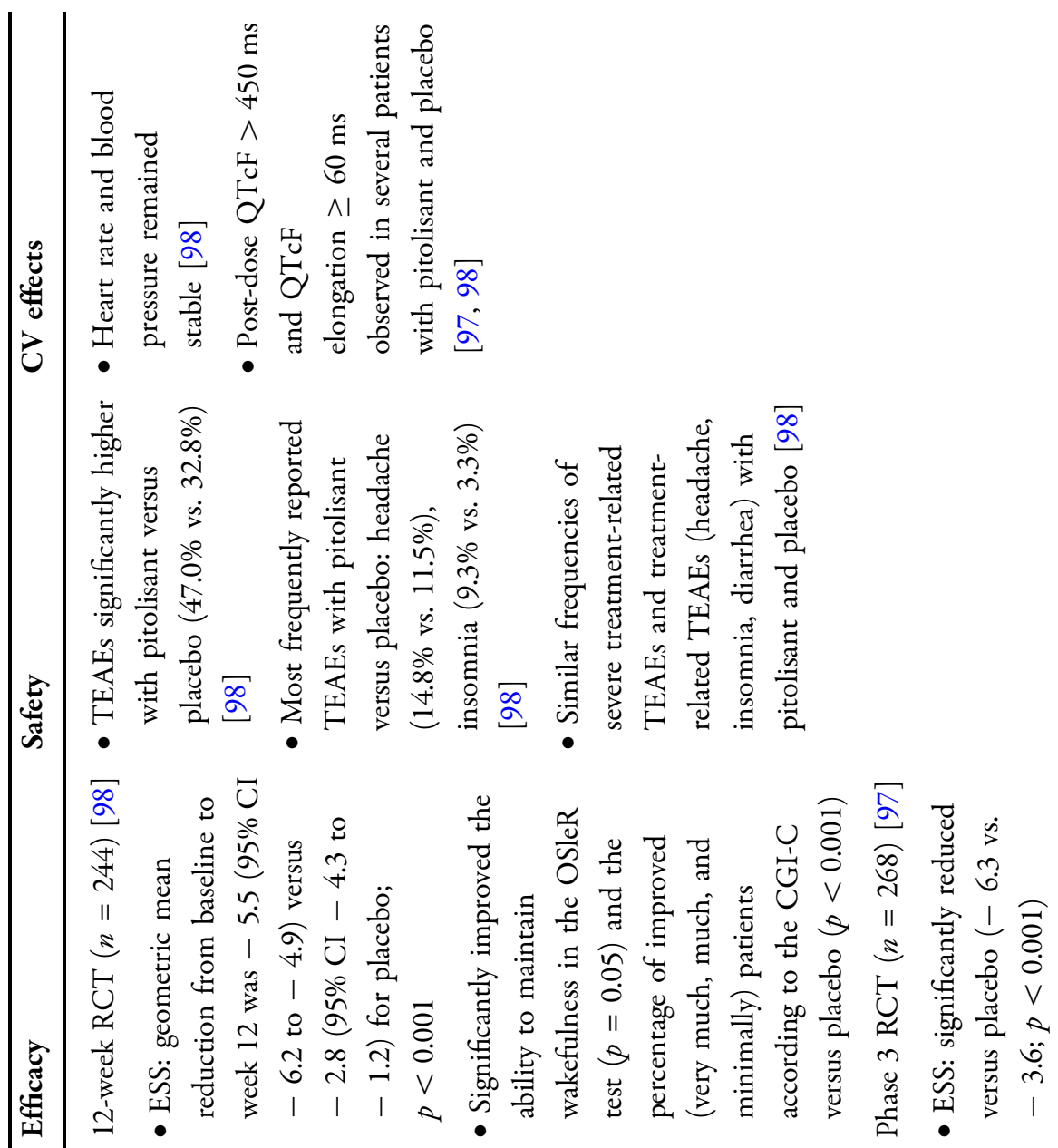

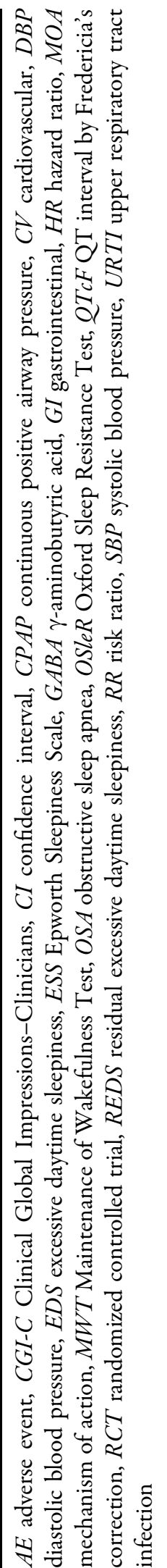


and SUVN-G3031, and have been recently reviewed in detail [109].

\section{CONCLUSIONS}

REDS, despite adherence to CPAP, is challenging to evaluate and treat, and is associated with considerable health burden. Multifactorial pathophysiologic mechanisms, including chronic hypoxia-reoxygenation-induced injury to orexinergic neurons, genetic factors, oxidative stress, dysbiosis, inflammatory issues, altered melatonin circadian rhythms, sleep fragmentation, and possible disturbances of the glymphatic system, may not be completely reversed after OSA is treated. Subjective measures of sleepiness, such as the ESS, may have limited effectiveness in identifying patients with REDS; thus, referral of patients to a sleep specialist for objective testing is necessary to correctly identify those requiring further treatment. Initial management of REDS due to OSA includes evaluation of comorbidities, replacing sleep-promoting medications, and optimizing CPAP efficiency. Wake-promoting medications are available where clinically appropriate.

Long-term studies are needed to confirm the $\mathrm{CV}$ safety of current wake-promoting medications. Real-world population-based studies on the effects of treatments on reducing car accidents and CV events (e.g., stroke, hypertension), as well as improving QoL, are also needed. In addition, evidence-based guidelines providing recommendations for the management of REDS and outlining the role of cardiologists in a multidisciplinary team are needed.

\section{ACKNOWLEDGEMENTS}

Funding. Funding for this manuscript and the journal's Rapid Service Fee was provided by Jazz Pharmaceuticals through an unrestricted educational grant. Jazz Pharmaceuticals had no control over the content and development of this manuscript.
Medical Writing and Editorial Assistance. Andrea Bothwell of inScience Communications (New York, NY, USA) and Elizabeth Samander of Springer Healthcare (New York, NY, USA) provided medical writing support. Brad Zerlanko of Springer Healthcare (Jersey City, NJ, USA) provided editorial support. This assistance was funded by an unrestricted medical education grant from Jazz Pharmaceuticals (Palo Alto, CA, USA).

Authorship. All named authors meet the International Committee of Medical Journal Editors (ICMJE) criteria for authorship for this article, take responsibility for the integrity of the work as a whole, and have given their approval for this version to be published.

Authors' Contributions. The authors equally participated in the development of the manuscript, had full editorial control, reviewed and edited various drafts, and provided their final approval of all content and submission for publication.

Disclosures. Reena Mehra reports receiving National Institutes of Health funding support from the National Heart, Lung, and Blood Institute [U01HL125177, UG3HL140144] and the American Heart Association. She has also received funds for service on the American Board of Medicine Sleep Medicine Exam test writing committee, Associate Editor of the American Journal of Respiratory and Critical Care Medicine, and royalties from UpToDate. Raphael Heinzer is member of the medical advisory board of Dreem and Nightbalance (Philips). He has received speaker's fees from Resmed, Philips, and Inspire. Raphael Heinzer also receives grant support from Apnimed and received grant support from Ligue pulmonaire Suisse from 2018 through 2020 . He is part of an adjudication committee of Nyxoah. Pablo Castillo has no financial disclosures to report.

Compliance with Ethics Guidelines. This article is based on previously conducted studies and does not contain any new studies with human participants or animals performed by any of the authors. 
Data Availability. Data sharing is not applicable to this article as no data sets were generated or analyzed for this review.

Open Access. This article is licensed under a Creative Commons Attribution-NonCommercial 4.0 International License, which permits any non-commercial use, sharing, adaptation, distribution and reproduction in any medium or format, as long as you give appropriate credit to the original author(s) and the source, provide a link to the Creative Commons licence, and indicate if changes were made. The images or other third party material in this article are included in the article's Creative Commons licence, unless indicated otherwise in a credit line to the material. If material is not included in the article's Creative Commons licence and your intended use is not permitted by statutory regulation or exceeds the permitted use, you will need to obtain permission directly from the copyright holder. To view a copy of this licence, visit http://creativecommons.org/licenses/bync/4.0/.

\section{REFERENCES}

1. Gasa M, Tamisier R, Launois $\mathrm{SH}$, et al. Scientific Council of the Sleep Registry of the French Federation of Pneumology-FFP. Residual sleepiness in sleep apnea patients treated by continuous positive airway pressure. J Sleep Res. 2013;22:389-97.

2. American Academy of Sleep Medicine. International classification of sleep disorders. 3rd ed. Darien: American Academy of Sleep Medicine; 2014.

3. Kapur VK, Auckley DH, Chowdhuri S, et al. Clinical practice guideline for diagnostic testing for adult obstructive sleep apnea: an American Academy of Sleep Medicine Clinical Practice Guideline. J Clin Sleep Med. 2017;13:479-504.

4. Benjafield AV, Ayas NT, Eastwood PR, et al. Estimation of the global prevalence and burden of obstructive sleep apnoea: a literature-based analysis. Lancet Respir Med. 2019;7:687-98.

5. Punjabi NM, Caffo BS, Goodwin JL, et al. Sleepdisordered breathing and mortality: a prospective cohort study. PLoS Med. 2009;6: e1000132.
6. Tietjens JR, Claman D, Kezirian EJ, et al. Obstructive sleep apnea in cardiovascular disease: a review of the literature and proposed multidisciplinary clinical management strategy. J Am Heart Assoc. 2019;8: e010440.

7. Javaheri S, Javaheri S. Update on persistent excessive daytime sleepiness in OSA. Chest. 2020;158: 776-86.

8. Ronksley PE, Hemmelgarn BR, Heitman SJ, et al. Excessive daytime sleepiness is associated with increased health care utilization among patients referred for assessment of OSA. Sleep. 2011;34: 363-70.

9. Hassed C, Antoniades J, Jones K, et al. An examination of Australian general practitioners' knowledge, attitudes, and practices in relation to sleep disorders. Malays Fam Physician. 2012;7:16-23.

10. Mazzotti DR, Keenan BT, Lim DC, Gottlieb DJ, Kim J, Pack AI. Symptom subtypes of obstructive sleep apnea predict incidence of cardiovascular outcomes. Am J Respir Crit Care Med. 2019;200: 493-506.

11. Sadeh A, Gruber R, Raviv A. Sleep, neurobehavioral functioning, and behavior problems in school-age children. Child Dev. 2002;73:405-17.

12. Medic G, Wille M, Hemels ME. Short- and longterm health consequences of sleep disruption. Nat Sci Sleep. 2017;9:151-61.

13. Garbarino S. Excessive daytime sleepiness in obstructive sleep apnea: implications for driving licenses. Sleep Breath. 2020;24:37-47.

14. Kayaba M, Matsushita T, Enomoto M, et al. Impact of sleep problems on daytime function in school life: a cross-sectional study involving Japanese university students. BMC Public Health. 2020;20:371.

15. Waldman LT, Parthasarathy S, Villa KF, Bron M, Bujanover S, Brod M. Understanding the burden of illness of excessive daytime sleepiness associated with obstructive sleep apnea: a qualitative study. Health Qual Life Outcomes. 2020;18:128.

16. Shochat T, Cohen-Zion M, Tzischinsky O. Functional consequences of inadequate sleep in adolescents: a systematic review. Sleep Med Rev. 2014;18: 75-87.

17. Owens JA, Babcock D, Weiss M. Evaluation and treatment of children and adolescents with excessive daytime sleepiness. Clin Pediatr (Phila). 2020;59:340-51.

18. Marshall NS, Barnes M, Travier N, et al. Continuous positive airway pressure reduces daytime sleepiness 
in mild to moderate obstructive sleep apnoea: a meta-analysis. Thorax. 2006;61:430-4.

19. Pepin JL, Viot-Blanc V, Escourrou P, et al. Prevalence of residual excessive sleepiness in CPAP-treated sleep apnoea patients: the French multicentre study. Eur Respir J. 2009;33:1062-7.

20. Weaver TE, Maislin G, Dinges DF, et al. Relationship between hours of CPAP use and achieving normal levels of sleepiness and daily functioning. Sleep. 2007;30:711-9.

21. Koutsourelakis I, Perraki E, Economou NT, et al. Predictors of residual sleepiness in adequately treated obstructive sleep apnoea patients. Eur Respir J. 2009;34:687-93.

22. Antic NA, Catcheside P, Buchan C, et al. The effect of CPAP in normalizing daytime sleepiness, quality of life, and neurocognitive function in patients with moderate to severe OSA. Sleep. 2011;34:111-9.

23. Budhiraja R, Kushida CA, Nichols DA, et al. Predictors of sleepiness in obstructive sleep apnoea at baseline and after 6 months of continuous positive airway pressure therapy. Eur Respir J. 2017;50: 1700348.

24. Gruber R, Constantin E, Frappier JY, Brouillette RT, Wise MS. Training, knowledge, attitudes and practices of Canadian health care providers regarding sleep and sleep disorders in children. Paediatr Child Health. 2017;22:322-7.

25. Saleem AH, Al Rashed FA, Alkharboush GA, et al. Primary care physicians' knowledge of sleep medicine and barriers to transfer of patients with sleep disorders. A cross-sectional study. Saudi Med J. 2017;38:553-9.

26. Veasey SC, Davis CW, Fenik P, et al. Long-term intermittent hypoxia in mice: protracted hypersomnolence with oxidative injury to sleep-wake brain regions. Sleep. 2004;27:194-201.

27. Zhan G, Serrano F, Fenik P, et al. NADPH oxidase mediates hypersomnolence and brain oxidative injury in a murine model of sleep apnea. Am J Respir Crit Care Med. 2005;172:921-9.

28. Parekh A, Mullins AE, Kam K, Varga AW, Rapoport DM, Ayappa I. Slow-wave activity surrounding stage N2 K-complexes and daytime function measured by psychomotor vigilance test in obstructive sleep apnea. Sleep. 2019;42:1-13. https://doi.org/10. 1093/sleep/zsy256.

29. Barnas M, Maskey-Warzechowska M, Bielicki P, Kumor M, Chazan R. Diurnal and nocturnal serum melatonin concentrations after treatment with continuous positive airway pressure in patients with obstructive sleep apnea. Pol Arch Intern Med. 2017;127:589-96.

30. Iliff JJ, Wang M, Liao Y, et al. A paravascular pathway facilitates CSF flow through the brain parenchyma and the clearance of interstitial solutes, including amyloid $\beta$. Sci Transl Med. 2012;4: 147 ra111.

31. Xiong Y, Zhou XJ, Nisi RA, et al. Brain white matter changes in CPAP-treated obstructive sleep apnea patients with residual sleepiness. J Magn Reson Imaging. 2017;45:1371-8.

32. Owen JE, BenediktsdÓttir B, Gislason T, Robinson SR. Neuropathological investigation of cell layer thickness and myelination in the hippocampus of people with obstructive sleep apnea. Sleep. 2019;42: 1-13. https://doi.org/10.1093/sleep/zsy199.

33. Marchi NA, Ramponi C, Hirotsu C, et al. Mean oxygen saturation during sleep is related to specific brain atrophy pattern. Ann Neurol. 2020;87: 921-30.

34. Dergacheva O, Yamanaka A, Schwartz AR, Polotsky VY, Mendelowitz D. Hypoxia and hypercapnia inhibit hypothalamic orexin neurons in rats. J Neurophysiol. 2016;116:2250-9.

35. Du MK, Hunt NJ, Waters KA, Machaalani R. Cumulative effects of repetitive intermittent hypercapnic hypoxia on orexin in the developing piglet hypothalamus. Int J Devl Neurosci. 2016;48: $1-8$.

36. Han F, Mignot E, Wei YC, et al. Ventilatory chemoresponsiveness, narcolepsy-cataplexy and human leukocyte antigen DQB1*0602 status. Eur Respir J. 2010;36:577-83.

37. Dergacheva O, Philbin K, Bateman R, Mendelowitz D. Hypocretin-1 (orexin A) prevents the effects of hypoxia/hypercapnia and enhances the GABAergic pathway from the lateral paragigantocellular nucleus to cardiac vagal neurons in the nucleus ambiguus. Neuroscience. 2011;175:18-23.

38. Yuan LB, Dong HL, Zhang HP, et al. Neuroprotective effect of orexin-A is mediated by an increase of hypoxia-inducible factor- 1 activity in rat. Anesthesiology. 2011;114:340-54.

39. Sokołowska P, Urbańska A, Biegańska K, et al. Orexins protect neuronal cell cultures against hypoxic stress: an involvement of Akt signaling. J Mol Neurosci. 2014;52:48-55.

40. Terada J, Nakamura A, Zhang W, et al. Ventilatory long-term facilitation in mice can be observed during both sleep and wake periods and depends on orexin. J Appl Physiol. 1985;2008(104):499-507. 
41. Han F. Respiratory regulation in narcolepsy. Sleep Breath. 2012;16:241-5.

42. Feng Y, Liu T, Li XQ, et al. Neuroprotection by orexin-A via HIF- $1 \alpha$ induction in a cellular model of Parkinson's disease. Neurosci Lett. 2014;579:35-40.

43. Li G, Tang S, Chi H, et al. Orexin-A aggravates the impairment of hippocampal neurons caused by intermittent hypoxemia by the OXR-PLC $\beta 1$-ERK1/2 pathway. NeuroReport. 2017;28:331-8.

44. Dergacheva O. Chronic intermittent hypoxia alters neurotransmission from lateral paragigantocellular nucleus to parasympathetic cardiac neurons in the brain stem. J Neurophysiol. 2015;113:380-9.

45. Dergacheva O, Mendelowitz D. Combined hypoxia and hypercapnia, but not hypoxia alone, suppresses neurotransmission from orexin to hypothalamic paraventricular spinally-projecting neurons in weanling rats. Brain Res. 2018;1679:33-8.

46. Veasey SC, Zhan G, Fenik P, Pratico D. Long-term intermittent hypoxia: reduced excitatory hypoglossal nerve output. Am J Respir Crit Care Med. 2004;170:665-72.

47. Zhu Y, Fenik P, Zhan G, Xin R, Veasey SC. Degeneration in arousal neurons in chronic sleep disruption modeling sleep apnea. Front Neurol. 2015;6: 109.

48. Mehra R, Wang L, Andrews N, et al. Dissociation of objective and subjective daytime sleepiness and biomarkers of systemic inflammation in sleep-disordered breathing and systolic heart failure. J Clin Sleep Med. 2017;13:1411-22.

49. Randerath W, Bassetti CL, Bonsignore MR, et al. Challenges and perspectives in obstructive sleep apnoea: report by an ad hoc working group of the Sleep Disordered Breathing Group of the European Respiratory Society and the European Sleep Research Society. Eur Respir J. 2018;52:1702616.

50. Chen HL, Lu CH, Lin HC, et al. White matter damage and systemic inflammation in obstructive sleep apnea. Sleep. 2015;38:361-70.

51. Xie L, Kang H, Xu Q, et al. Sleep drives metabolite clearance from the adult brain. Science. 2013;342: 373-7.

52. Demiral SB, Tomasi D, Sarlls J, et al. Apparent diffusion coefficient changes in human brain during sleep-does it inform on the existence of a glymphatic system? Neuroimage. 2019;185:263-73.

53. Smith RP, Easson C, Lyle SM, et al. Gut microbiome diversity is associated with sleep physiology in humans. PLoS ONE. 2019;14: e0222394.
54. Durgan DJ, Ganesh BP, Cope JL, et al. Role of the gut microbiome in obstructive sleep apnea-induced hypertension. Hypertension. 2016;67:469-74.

55. Chen X, Wang R, Zee P, et al. Racial/ethnic differences in sleep disturbances: the multi-ethnic study of atherosclerosis (MESA). Sleep. 2015;38:877-88.

56. Barfield RH, Wang Y, Liu J, et al. Epigenome-wide association analysis of daytime sleepiness in the Multi-Ethnic Study of Atherosclerosis reveals African-American-specific associations. Sleep. 2019;42: zsz101.

57. Prasad B, Steffen AD, Van Dongen HP, et al. Determinants of sleepiness in obstructive sleep apnea. Sleep. 2018;41:1-9. https://doi.org/10.1093/sleep/ zsx199.

58. Haentjens P, Van Meerhaeghe A, Moscariello A, et al. The impact of continuous positive airway pressure on blood pressure in patients with obstructive sleep apnea syndrome: evidence from a meta-analysis of placebo-controlled randomized trials. Arch Intern Med. 2007;167:757-64.

59. Montesi SB, Edwards BA, Malhotra A, Bakker JP. The effect of continuous positive airway pressure treatment on blood pressure: a systematic review and meta-analysis of randomized controlled trials. J Clin Sleep Med. 2012;8:587-96.

60. Sánchez-de-la-Torre M, Sánchez-de-la-Torre A, Bertran S, et al. Effect of obstructive sleep apnoea and its treatment with continuous positive airway pressure on the prevalence of cardiovascular events in patients with acute coronary syndrome (ISAACC study): a randomised controlled trial. Lancet Respir Med. 2020;8:359-67.

61. Continuous positive airway pressure (CPAP) in patients with acute coronary syndrome and obstructive sleep apnea (OSA) (ISAACC). https:// clinicaltrials.gov/ct2/show/NCT01335087. Accessed 20 July 2021.

62. Shao C, Qi H, Lang R, et al. Clinical features and contributing factors of excessive daytime sleepiness in Chinese obstructive sleep apnea patients: the role of comorbid symptoms and polysomnographic variables. Can Respir J. 2019. https://doi.org/10. $1155 / 2019 / 5476372$.

63. LaGrotte C, Fernandez-Mendoza J, Calhoun SL, Liao D, Bixler EO, Vgontzas AN. The relative association of obstructive sleep apnea, obesity and excessive daytime sleepiness with incident depression: a longitudinal, population-based study. Int J Obes (Lond). 2016;40:1397-404.

64. Lakshminarayanan S, Paramasivan KD, Walters AS, Wagner ML, Patel S, Passi V. Clinically significant 
but unsuspected restless legs syndrome in patients with sleep apnea. Mov Disord. 2005;20:501-3.

65. Lang CJ, Appleton SL, Vakulin A, et al. Associations of undiagnosed obstructive sleep apnea and excessive daytime sleepiness with depression: an Australian population study. J Clin Sleep Med. 2017;13: 575-82.

66. Maugeri A, Medina-Inojosa JR, Kunzova S, et al. Sleep duration and excessive daytime sleepiness are associated with obesity independent of diet and physical activity. Nutrients. 2018;10:1219.

67. Huang CY, Yu CC. Different diagnostic criteria for periodic leg movements in patients with obstructive sleep apnea after continuous positive airway pressure titration. Neuropsychiatr Dis Treat. 2019;15: 2129-36.

68. Jackson-Koku G. Beck depression inventory. Occup Med (Lond). 2016;66:174-5.

69. Jahrami H, BaHammam AS, Bragazzi NL, Saif Z, Faris M, Vitiello MV. Sleep problems during the COVID19 pandemic by population: a systematic review and meta-analysis. J Clin Sleep Med. 2021;17: 299-313.

70. Miller MA, Cappuccio FP. A systematic review of COVID-19 and obstructive sleep apnoea. Sleep Med Rev. 2021;55: 101382.

71. BaHammam AS. Treatment-emergent central sleep apnea (complex sleep apnea). Sleep Vigil. 2017;1: 53-6.

72. Besedovsky L, Lange T, Haack M. The sleep-immune crosstalk in health and disease. Physiol Rev. 2019;99:1325-80.

73. Haack M, Simpson N, Sethna N, Kaur S, Mullington J. Sleep deficiency and chronic pain: potential underlying mechanisms and clinical implications. Neuropsychopharmacology. 2020;45:205-16.

74. Griffin CE III, Kaye AM, Bueno FR, Kaye AD. Benzodiazepine pharmacology and central nervous system-mediated effects. Ochsner J. 2013;13: 214-23.

75. Paus S, Brecht HM, Koster J, Seeger G, Klockgether T, Wullner U. Sleep attacks, daytime sleepiness, and dopamine agonists in Parkinson's disease. Mov Disord. 2003;18:659-67.

76. Myc LA, Churnin IT, Jameson MJ, Davis EM. Treatment of comorbid obstructive sleep apnea by upper airway stimulation results in resolution of debilitating symptoms of restless legs syndrome. J Clin Sleep Med. 2018;14:1797-800.
77. Schwab RJ. Periodic limb movement disorder (PLMD) and restless legs syndrome (RLS). Merck Manual Professional Version website. https://www. merckmanuals.com/professional/neurologicdisorders/sleep-and-wakefulness-disorders/periodiclimb-movement-disorder-plmd-and-restless-legssyndrome-rls. Updated June 2020. Accessed July 23, 2021.

78. Farzam K, Sabir S, O'Rourke MC. Antihistamines. NCBI Bookshelf website. StatPearls Publishing; January 2021. https://www.ncbi.nlm.nih.gov/books/ NBK538188/. Updated May 28, 2021. Accessed July 23, 2021.

79. Farzam K, Jan A. Beta blockers. NCBI Bookshelf website. StatPearls Publishing; January 2021. https://www.ncbi.nlm.nih.gov/books/NBK532906/. Updated July 9, 2021. Accessed July 23, 2021.

80. Witenko C, Moorman-Li R, Motycka C, et al. Considerations for the appropriate use of skeletal muscle relaxants for the management of acute low back pain. P\&T. 2014;39:427-35.

81. Servantes DM, Javaheri S, Kravchychyn AC, et al. Effects of exercise training and CPAP in patients with heart failure and OSA: a preliminary study. Chest. 2018;154:808-17.

82. Kazemeini E, Braem MJ, Moorkens G, et al. Scoring of hypersomnolence and fatigue in patients with obstructive sleep apnea treated with a titratable custom-made mandibular advancement device. J Clin Sleep Med. 2019;15:623-8.

83. Dal-Fabbro C, Garbuio S, D'Almeida V, Cintra FD, Tufik S, Bittencourt L. Mandibular advancement device and CPAP upon cardiovascular parameters in OSA. Sleep Breath. 2014;18:749-59.

84. de Godoy LB, Palombini LO, Guilleminault C, Poyares D, Tufik S, Togeiro SM. Treatment of upper airway resistance syndrome in adults: where do we stand? Sleep Sci. 2015;8:42-8.

85. Stoohs RA, Knaack L, Blum HC, Janicki J, Hohenhorst W. Differences in clinical features of upper airway resistance syndrome, primary snoring, and obstructive sleep apnea/hypopnea syndrome. Sleep Med. 2008;9:121-8.

86. Johns MW. A new method for measuring daytime sleepiness: the Epworth Sleepiness Scale. Sleep. 1991;14:540-5.

87. Lapin BR, Bena JF, Walia HK, Moul DE. The Epworth Sleepiness Scale: validation of one-dimensional factor structure in a large clinical sample. J Clin Sleep Med. 2018;14:1293-301. 
88. Pilcher JJ, Switzer FS III, Munc A, Donnelly J, Jellen JC, Lamm C. Psychometric properties of the Epworth Sleepiness Scale: a factor analysis and itemresponse theory approach. Chronobiol Int. 2018;35: 533-45.

89. Leger D, Stepnowsky C. The economic and societal burden of excessive daytime sleepiness in patients with obstructive sleep apnea. Sleep Med Rev. 2020;51: 101275 .

90. Luyster FS, Choi J, Yeh CH, Imes CC, Johansson AE, Chasens ER. Screening and evaluation tools for sleep disorders in older adults. Appl Nurs Res. 2015;28:334-40.

91. O'Donnell D, Silva EJ, Munch M, Ronda JM, Wang W, Duffy JF. Comparison of subjective and objective assessments of sleep in healthy older subjects without sleep complaints. J Sleep Res. 2009;18: 254-63.

92. Littner MR, Kushida C, Wise $M$, et al. Practice parameters for clinical use of the Multiple Sleep Latency Test and the Maintenance of Wakefulness Test. Sleep. 2005;28:113-21.

93. Huang Y, Aumüller P, Fietze I, Penzel T, Veauthier C. Comparison of the oxford sleep resistance test and the multiple sleep latency test. Physiol Meas. 2020;41: 104005.

94. PROVIGIL ${ }^{\circledR}$ (modafinil) tablets [prescribing information]. North Wales, PA: Teva Pharmaceuticals USA, Inc.; January 2015.

95. NUVIGIL ${ }^{\circledR}$ (armodafinil) tablets [prescribing information]. North Wales, PA: Teva Pharmaceuticals USA, Inc.; November 2018.

96. European Medicines Agency recommends restricting the use of modafinil. European Medicines Agency website. https://www.ema.europa.eu/en/ news/european-medicines-agency-recommendsrestricting-use-modafinil. Updated July 7, 2010. Accessed July 23, 2021.

97. Dauvilliers Y, Verbraecken J, Partinen M, et al. Pitolisant for daytime sleepiness in patients with obstructive sleep apnea who refuse continuous positive airway pressure treatment. A randomized trial. Am J Respir Crit Care Med. 2020;201:1135-45.

98. Pepin JL, Georgiev O, Tiholov R, et al. Pitolisant for residual excessive daytime sleepiness in OSA patients adhering to CPAP: a randomized trial. Chest. 2021;159:1598-609.

99. Schweitzer PK, Rosenberg R, Zammit GK, et al. Solriamfetol for excessive sleepiness in obstructive sleep apnea (TONES 3). A randomized controlled trial. Am J Respir Crit Care Med. 2019;199:1421-31.
100. Chapman JL, Vakulin A, Hedner J, Yee BJ, Marshall NS. Modafinil/armodafinil in obstructive sleep apnoea: a systematic review and meta-analysis. Eur Respir J. 2016;47:1420-8.

101. SUNOSI ${ }^{\mathrm{TM}}$ (solriamfetol) tablets [prescribing information]. Palo Alto: Jazz Pharmaceuticals, Inc.; 2019.

102. Sunosi film-coated tablets (solriamfetol) [summary of product characteristics]. Oxford: Jazz Pharmaceuticals UK Limited; 2021.

103. Abad VC. Profile of solriamfetol in the management of excessive daytime sleepiness associated with narcolepsy or obstructive sleep apnea: focus on patient selection and perspectives. Nat Sci Sleep. 2021;13:75-91.

104. NCT01072968. BF2.649 in patients with OSA, still complaining of EDS and refusing to be treated by CPAP (HAROSA2). https://clinicaltrials.gov/ct2/ show/NCT01072968. Updated January 21, 2015. Accessed July 23, 2021.

105. NCT02978651. Pitolisant (BF2.649) in the treatment of excessive daytime sleepiness in patients with obstructive sleep apnoea syndrome, treated or not by nasal continuous positive airway pressure, but still complaining of excessive daytime sleepiness (HAROSA IV). https://clinicaltrials.gov/ct2/ show/NCT02978651. Updated November 24, 2017. Accessed Aug 9, 2021.

106. WAKIX ${ }^{\circledR}$ (pitolisant) tablets [prescribing information]. Plymouth Meeting, PA: Harmony Biosciences, LLC; 2021.

107. Pitolisant - Bioprojet. AdisInsight Drugs website. https://adisinsight.springer.com/drugs/800029451. Updated July 23, 2021. Accessed Aug 9, 2021.

108. Vom Nachrichtendienst. Bioprojet. Excessive daytime sleepiness in obstructive sleep apnoea syndrome: favourable opinion from the European Medicines Agency for Ozawade ${ }^{\mathrm{TM}}$. CISION ${ }^{\circledR}$ PR Newswire website. https://www.prnewswire.com/ de/pressemitteilungen/excessive-daytimesleepiness-in-obstructive-sleep-apnoea-syndromefavourable-opinion-from-the-european-medicinesagency-for-ozawade-tm-860835694.html. Published June 4, 2021. Accessed Aug 9, 2021.

109. Thorpy MJ. Recently approved and upcoming treatments for narcolepsy. CNS Drugs. 2020;34: 9-27.

110. NCT04091425. Study of TAK-925 in participants with obstructive sleep apnea (OSA) who are experiencing excessive daytime sleepiness (EDS) despite adequate use of continuous positive airway pressure (CPAP). https://clinicaltrials.gov/ct2/show/ 
NCT04091425. Updated April 20, 2020. Accessed July 23, 2021.

111. Shahid A, Wilkinson K, Marcu S, Shapiro CM. Fatigue assessment scale (FAS). In: Shahid A, Wilkinson K, Marcu S, Shapiro C, editors. STOP, THAT and one hundred other sleep scales. Berlin: Springer; 2011. p. 161-2.

112. Goodwin E, Hawton A, Green C. Using the fatigue severity scale to inform healthcare decision-making in multiple sclerosis: mapping to three quality-adjusted life-year measures (EQ5D-3L, SF-6D, MSIS8D). Health Qual Life Outcomes. 2019;17:136.

113. MacGregor KL, Funderburk JS, Pigeon W, Maisto SA. Evaluation of the PHQ-9 item 3 as a screen for sleep disturbance in primary care. J Gen Intern Med. 2012;27:339-44.

114. Neitzer A, Sun S, Doss S, Moran J, Schiller B. Beck Depression Inventory-Fast Screen (BDI-FS): an efficient tool for depression screening in patients with end-stage renal disease. Hemodial Int. 2012;16: 207-13.

115. Center for Epidemiological Studies-Depression. American Psychological Association website. https://www.apa.org/pi/about/publications/ caregivers/practice-settings/assessment/tools/ depression-scale\#. Published 2011. Accessed July 23, 2021.
116. Arand D, Bonnet M, Hurwitz T, Mitler M, Rosa R, Sangal RB. The clinical use of the MSLT and MWT. Sleep. 2005;28:123-44.

117. Collop NA, Tracy SL, Kapur V, et al. Obstructive sleep apnea devices for out-of-center (OOC) testing: technology evaluation. J Clin Sleep Med. 2011;7: 531-48.

118. Wisor J. Modafinil as a catecholaminergic agent: empirical evidence and unanswered questions. Front Neurol. 2013;4:139.

119. Kaplan S, Goehring EL Jr, Melamed-Gal S, NguyenKhoa BA, Knebel H, Jones JK. Modafinil and the risk of cardiovascular events: findings from three US claims databases. Pharmacoepidemiol Drug Saf. 2018;27:1182-90.

120. Zomorodi K, Chen D, Lee L, Swearingen D, Carter LP. A randomized, double-blind, placebo- and positive-controlled, 4-period crossover study of the effects of solriamfetol on QTcF intervals in healthy participants. Clin Pharmacol Drug Dev. 2021;10: 404-13.

121. Malhotra A, Shapiro C, Pepin JL, et al. Long-term study of the safety and maintenance of efficacy of solriamfetol (JZP-110) in the treatment of excessive sleepiness in participants with narcolepsy or obstructive sleep apnea. Sleep. 2020;43:1-11. https://doi.org/10.1093/sleep/zsz220. 